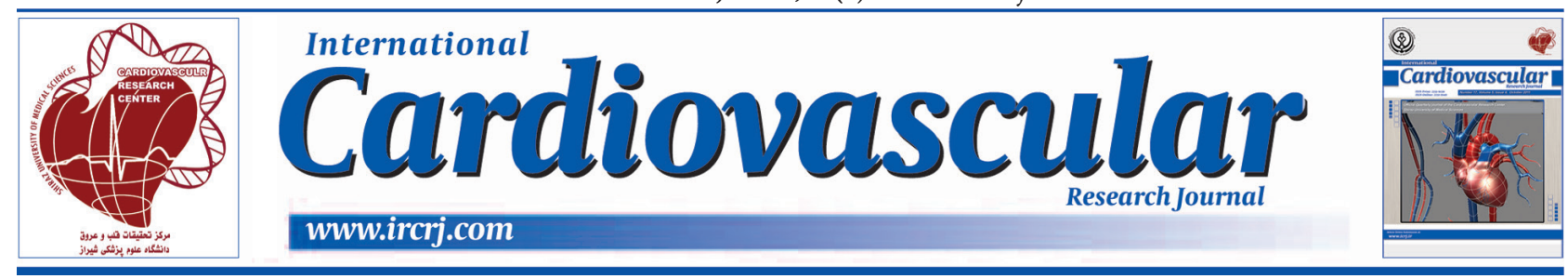

\title{
Anomalous Origin of Right Coronary Artery from Distal Left Circumflex Artery: A Very Rare Variant of Single Coronary Artery Anomaly
}

\author{
Arash Gholoobi ${ }^{1, *}$ \\ ${ }^{1}$ Atherosclerosis Prevention Research Center, Imam Reza Hospital, School of Medicine, Mashhad University of Medical Sciences, Mashhad, IR Iran
}

\begin{tabular}{|c|c|}
\hline A R T I C L E I N F O & A B S T R A C T \\
\hline $\begin{array}{l}\text { Article Type: } \\
\text { Case Report }\end{array}$ & $\begin{array}{l}\text { Anomalous origin of the right coronary artery from the distal left circumflex artery } \\
\text { is a very rare subtype of single coronary artery anomaly. Herein, a } 47 \text {-year-old man }\end{array}$ \\
\hline $\begin{array}{l}\text { Article History: } \\
\text { Received: 07 Dec } 2014 \\
\text { Revised: } 16 \text { May } 2015 \\
\text { Accepted: } 17 \text { Jun } 2015\end{array}$ & $\begin{array}{l}\text { to have anomalous origin of the right coronary artery from the distal left circumflex } \\
\text { artery in coronary angiography. This type of coronary anomaly is not associated with } \\
\text { other cardiac anomalies and does not raise the risk of sudden cardiac death. Besides, it } \\
\text { probably does not lead to myocardial ischemia in the absence of coronary atherosclerosis } \\
\text { in most instances and may not accelerate the atherosclerotic process. }\end{array}$ \\
\hline
\end{tabular}

Coronary Vessel Anomalies

Coronary Artery Disease

Coronary Angiography

Implication for health policy/practice/research/medical education:

The anomalous origin of the RCA from the distal LCx is a very rare variant of SCA. This specific subtype of coronary anomaly is not associated with great vessels; however, it might lead to myocardial ischemia in some patients even in the absence of atherosclerotic lesions. Also, it is not associated with other structural cardiac anomalies. Altogether, it seems to be a benign coronary anomaly per se.

\section{Introduction}

Among coronary anomalies, Single Coronary Artery (SCA) is a rare anomaly in which one coronary artery stems from a single coronary ostium from the aortic sinuses, nourishing the entire heart. A very rare subtype of this anomaly is the anomalous origin of the Right Coronary Artery (RCA) from the distal Left Circumflex (LCx) artery.

\section{Case Presentation}

A 47-year-old man was referred for coronary angiography due to stable ischemic heart disease [The Canadian Cardiovascular Society (CCS) class II-III]. He had a history of dyslipidemia and antero-septal myocardial infarction since 3 years ago, managed medically. His physical examination was unremarkable, except for an S4 heard on cardiac auscultation. Additionally, 12-lead

*Corresponding author: Arash Gholoobi, Department of Cardiology, Imam Reza Hospital, Ebne Sina Ave., Mashhad, Iran. Postal Code: 9137913316 Tel/Fax: +98-5138544504,

E-mail: gholoobia@mums.ac.ir electrocardiography showed normal sinus rhythm with Q waves in V1 - V3 precordial leads (Figure 1). Transthoracic echocardiography also revealed antero-septal and anterior wall hypokinesia with a left ventricular ejection fraction of $30-35 \%$ and mild mitral regurgitation; there were no apparent types of major cardiac anomalies.

In coronary angiography, the Left Anterior Descending (LAD) artery was cut off just after the first septal branch. The distal LAD artery was filled in via collaterals with good run off. The Ramus Intermedius branch also had a moderate tubular stenosis at mid portion with good distal run off. The distal obtuse marginal branch was a well-developed artery with significant tubular stenosis at proximal part and good distal run off. The RCA aroused from the distal LCx artery and followed the course of the normal RCA distribution retrogradely, terminating near the right sinus of valsalva (Figures 2, 3 and Videos 1, 2 [to see the videos referee to the HTML format]). Aortic root injection confirmed the absence of RCA ostium anywhere in the coronary sinuses as well as in the ascending aorta (Figure 4 and Video 3). 

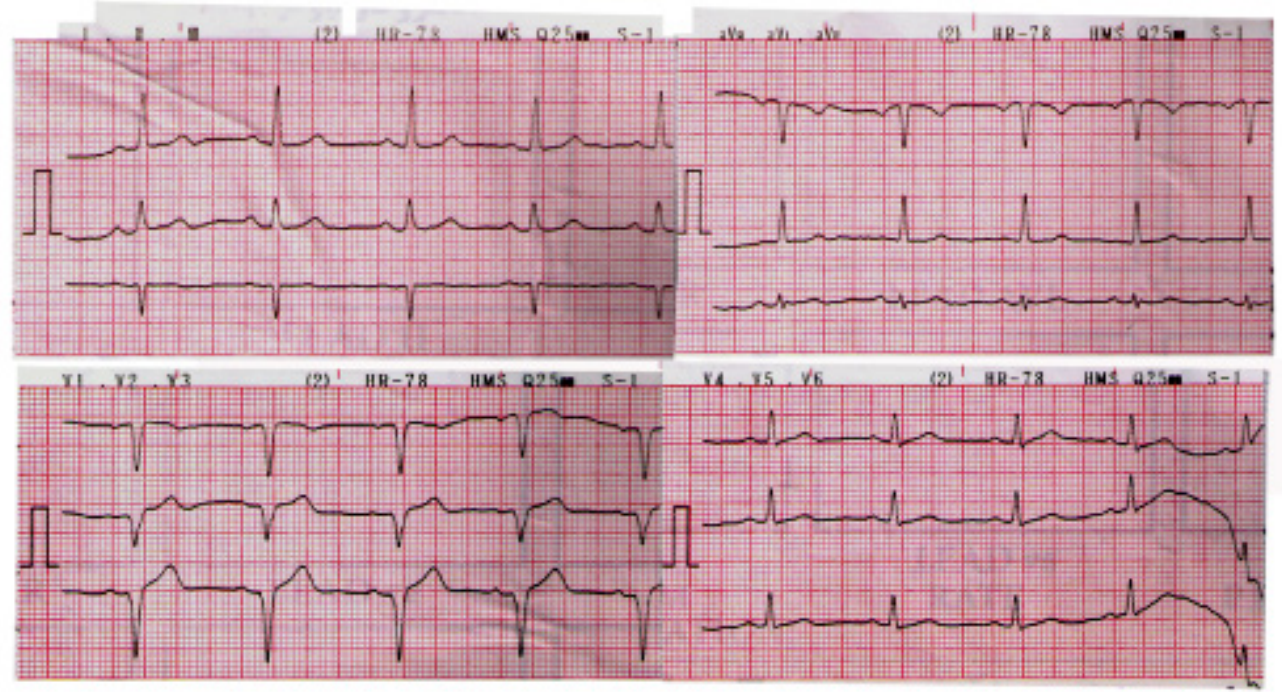

Figure 1. 12-Lead Electrocardiography Showed Q Waves in V1 - V3 Precordial Leads, Implicating an Old Antero-Septal Myocardial Infarction

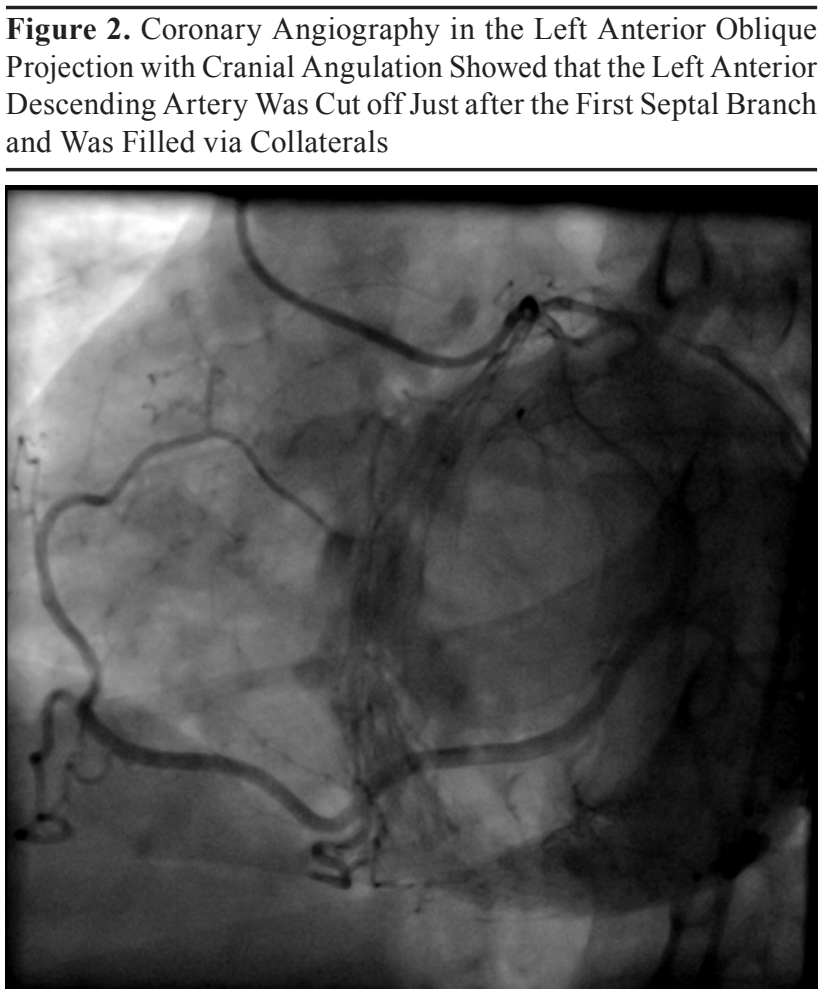

The right coronary artery aroused from the distal left circumflex artery and followed the course of the normal right coronary artery distribution retrogradely.

The patient underwent coronary artery bypass grafting.

\section{Discussion}

SCA is a rare anomaly of the coronary arteries, which is usually associated with other congenital cardiac malformations, such as transposition of the great vessels, coronary arterio-venous fistula, bicuspid aortic valve, and tetralogy of Fallot (1). The anomalous origin of the RCA from the distal LCX is a very rare variant of SCA, which has not been reported to be associated with other cardiac anomalies so far (1-7).

SCA anomaly could lead to myocardial ischemia and sudden cardiac death in the absence of coronary
Figure 3. Coronary Angiography in the Antero-Posterior Projection with Cranial Angulation Showed that the Left Anterior Descending Artery Was Cut off Just after the First Septal Branch and Was Filled via Collaterals

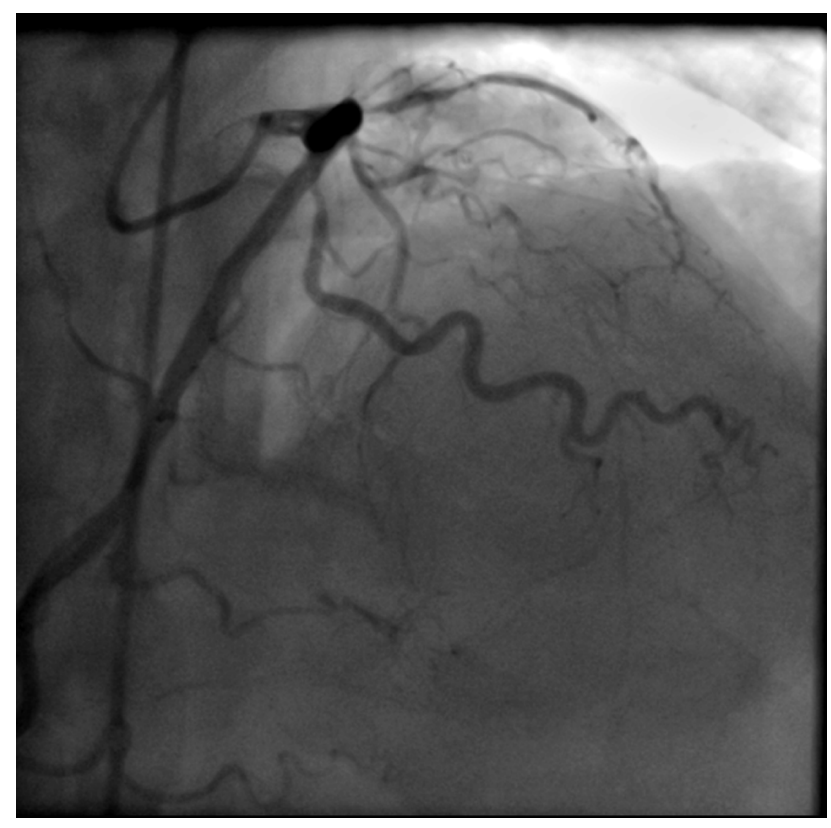

In this view, the left circumflex artery demonstrated itself as a super dominant artery.

atherosclerosis, especially in cases with anomalous coronary artery from the opposite sinus of valsalva and inter-arterial course of the aberrant artery (6). Still, this subtype of SCA anomaly does not seem to pose patients to sudden cardiac death or myocardial ischemia per se $(2,6$, 7). However, Chou et al. reported a patient with this type of anomaly in whom antero- apical myocardial ischemia was demonstrated on Thallium-201 heart scan along with horizontal ST-segment depressions at treadmill exercise testing in the presence of a normal but small LAD artery. The antero-apical ischemia was attributed to the small-sized LAD artery and its branches, which terminated before the apex (4). In our patient, although the LAD artery was cut 


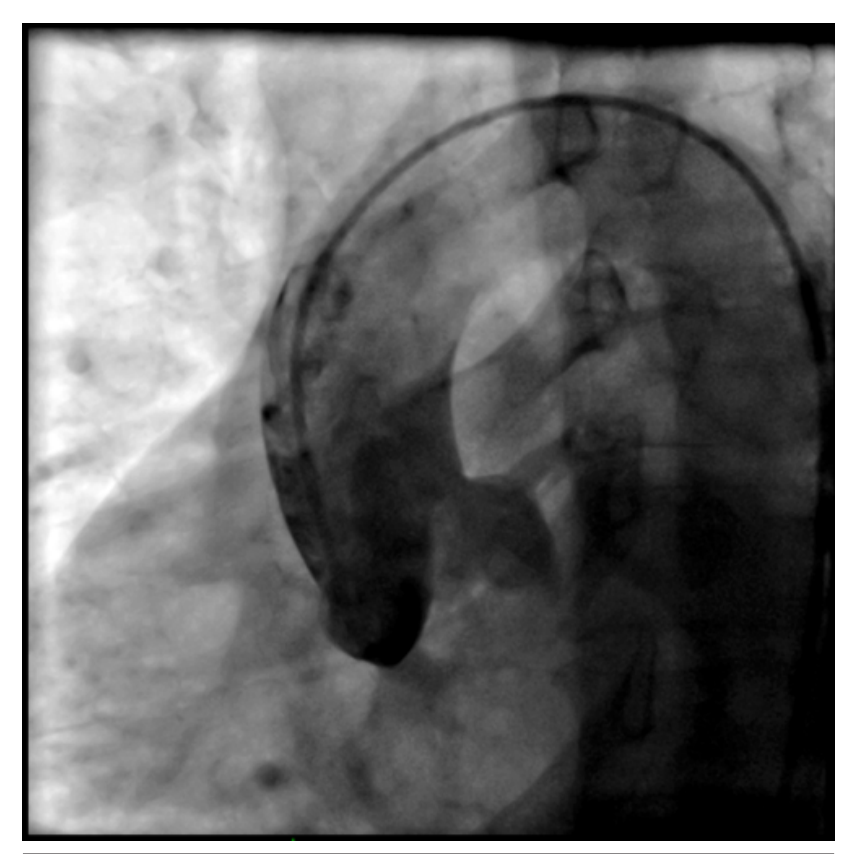

Figure 4. Aortic Root Injection in Straight Left Anterior Oblique Projection Confirmed the Absence of the Right Coronary Artery Ostium Anywhere in the Coronary Sinuses as Well as in the Ascending

off after the first septal branch, it reached the apex when it was filled via collaterals. Furthermore, in some other case reports, the LAD artery was not diminutive $(3,7)$. Arslan et al. reported another case with this type of anomaly and no atherosclerotic disease who developed horizontal STsegment depressions at stress electrocardiography, which was attributed to thinning of the anomalous RCA (3).

Whether anomalous origin and course of the coronary arteries predispose patients to accelerated atherosclerosis still remains controversial. A report from the Coronary Artery Surgery Study (CASS) on coronary artery anomalies that compared the degree of stenosis in anomalous coronary arteries to control patients without coronary anomalies indicated no significant increase in the rate of atherosclerosis in the anomalous coronary arteries, except for anomalous circumflex arteries (5). A vast majority of these patients might survive until coronary artery disease develops depending on the usual atherosclerotic risk factors leading to symptomatic coronary artery disease, as in our patient. In summary, this peculiar subtype of SCA anomaly seems to be a benign one and is not associated with other cardiac anomalies or sudden cardiac death. However, it could potentially lead to myocardial ischemia in some patients even in the absence of atherosclerotic lesions.

\section{Acknowledgements}

There is no acknowledgement.

\section{Authors' Contribution}

The manuscript is an original work by the author. All data, figures, etc. used in the manuscript are prepared originally by the author.

\section{Financial disclosure}

The author has no financial interests related to the material in the manuscript.

\section{Funding/Support}

There is no funding/support.

\section{References}

1. Ogden JA, Goodyer AV. Patterns of distribution of the single coronary artery. Yale J Biol Med. 1970;43(1):11-21.

2. Akcay A, Tuncer C, Batyraliev T, Gokce M, Eryonucu B, Koroglu $\mathrm{S}$, et al. Isolated single coronary artery: a series of 10 cases. Circ J. 2008;72(8):1254-8.

3. Arslan U, Karamanlioglu M, Korkmaz A. Conventional and computed tomography angiography views of a rare type of single coronary artery anomaly: right coronary artery arising from distal left circumflex artery. Anadolu Kardiyol Derg. 2012;12(6):522-3.

4. Chou LP, Kao C, Lee MC, Lin SL. Right coronary artery originating from distal left circumflex artery in a patient with an unusual type of isolated single coronary artery. Jpn Heart J. 2004;45(2):337-42.

5. Click RL, Holmes DR, Jr., Vlietstra RE, Kosinski AS, Kronmal RA. Anomalous coronary arteries: location, degree of atherosclerosis and effect on survival--a report from the Coronary Artery Surgery Study. J Am Coll Cardiol. 1989;13(3):531-7.

6. Shirani J, Roberts WC. Solitary coronary ostium in the aorta in the absence of other major congenital cardiovascular anomalies. $J \mathrm{Am}$ Coll Cardiol. 1993;21(1):137-43.

7. Turhan H, Duru E, Yetkin E, Atak R, Senen K. Right coronary artery originating from distal left circumflex: an extremely rare variety of single coronary artery. Int J Cardiol. 2003;88(2-3):309-11. 